\title{
Expression of mesenchymal-related genes by the bovine trophectoderm following conceptus attachment to the endometrial epithelium
}

\author{
Sachiko Yamakoshi, Rulan Bai, Takashi Chaen, Atsushi Ideta ${ }^{1}$, Yoshito Aoyagi ${ }^{1}$, Toshihiro Sakurai, \\ Toshihiro Konno and Kazuhiko Imakawa \\ Laboratory of Animal Breeding, Graduate School of Agricultural and Life Sciences, The University of Tokyo, 1-1-1 \\ Yayoi, Bunkyo-ku, Tokyo 113-8657, Japan and ${ }^{1}$ Zen-noh ET Center, Kamishihoro, Hokkaido 080-1407, Japan \\ Correspondence should be addressed to K Imakawa; Email: akaz@mail.ecc.u-tokyo.ac.jp
}

S Yamakoshi and R Bai contributed equally to this work

\begin{abstract}
In the course of experiments to identify and characterize the factors that function in bovine conceptuses during peri-attachment periods, various transcripts related to the epithelial-mesenchymal transition (EMT) were found. In this study, RNA was extracted from different sets of days 17, 20, and 22 (day $0=$ day of estrous) bovine conceptuses and subjected to real-time PCR analysis as well as Western blotting, from which abundances of $\mathrm{N}$-cadherin (CDH2), vimentin, matrix metalloproteinase 2 (gelatinase $\mathrm{A}, 72 \mathrm{kDa}$ gelatinase, $72 \mathrm{kDa}$ type IV collagenase) (MMP2), and matrix metallopeptidase 9 (gelatinase B, 92 kDa gelatinase, 92 kDa type IV collagenase) (MMP9) mRNAs were determined on day 22, concurrent with (CDH1) mRNA and protein downregulation. Transcription factors in EMT processes were then analyzed and changes in snail homolog 2 (Drosophila) (SNAI), zinc finger E-box binding homeobox 1 (ZEB1), zinc finger E-box binding homeobox 2 (ZEB2), twist homolog 1 (Drosophila) (TWIST1), twist homolog 2 (Drosophila) (TWIST2), and Kruppel-like factor 8 (KLF8) transcripts were found in day 22 conceptuses, while confirming SNAI2 expression by Western blotting. Immunohistochemical analysis revealed that the day 22 trophectoderm expressed the mesenchymal markers $\mathrm{N}$-cadherin and vimentin as well as the epithelial marker cytokeratin. In attempts to identify the molecular mechanisms by which the trophectoderm expressed EMT-related genes, growth factor receptors associated with EMT were analyzed. Upregulation of the growth factor receptor transcripts, fibroblast growth factor receptor 1 (FGFR1), platelet-derived growth factor receptor, alpha polypeptide (PDGFRA), platelet-derived growth factor receptor, beta polypeptide (PDGFRB), and transforming growth factor, beta receptor II (70/80 kDa) (TGFBR2) mRNAs, was found on day 22 . The analysis was extended to determine the integrin (ITG) transcripts and found high levels of integrin, alpha 4 (antigen CD49D, alpha 4 subunit of VLA-4 receptor) (ITGA4), integrin, alpha 8 (ITGA8), integrin, beta 3 (platelet glycoprotein IIla, antigen CD61) (ITGB3), and integrin, beta 5 (ITGB5) mRNAs on day 22. These observations indicate that after the conceptus-endometrium attachment, EMT-related transcripts as well as the epithelial marker cytokeratin were present in the bovine trophectoderm and suggest that the implantation process for noninvasive trophoblasts requires not only extracellular matrix expression but also partial EMT.
\end{abstract}

Reproduction (2012) 143 377-387

\section{Introduction}

Embryo implantation is an essential process for viviparity (Amoroso 1968) that differs among species and includes both noninvasive and invasive trophoblasts. However, the implantation process invariably begins from blastocyst migration, apposition, attachment, and adhesion to the epithelial lining of the endometrium (Bowen \& Burghardt 2000). At the preimplantation stage of embryo development, the first cell fate specification results in the segregation of the inner cell mass and trophectoderm (Nishioka et al. 2009). The trophectoderm forms the epithelial structure of the blastocyst and possesses epithelial characteristics, including apicobasal cell polarity, lateral junctions with neighboring cells, and basal contact with the basement membrane proteins (Biggers et al. 1988, Kang et al. 1990, Thorsteinsdóttir 1992, Fleming et al. 2001). Despite the fact that the apical plasma membranes of simple epithelia normally lack adhesive properties, the trophectoderm still manages to adhere to the uterine epithelium through its apical domains as part of the implantation process. Thus, the adhesion between trophectoderm and uterine epithelium has long been considered a cell biological paradox (Denker 1993).

Successive phases of implantation are classified as 1 ) shedding of the zona pellucida (ZP), 2) precontact 
stage and blastocyst orientation, 3) apposition and attachment, 4) adhesion, and 5) invasion (ChavattePalmer \& Guillomot 2007, Bazer et al. 2009). With the exception of rodents and primates, in which the conceptus enters a receptive uterus and attaches immediately to the uterine epithelium, most domestic animals have a prereceptive phase during which the conceptus does not physically interact with the uterine epithelium. Ruminant species such as sheep and cows have superficial/central implantation, in which a prolonged preattachment period is followed by incremental apposition and attachment of the conceptus to the luminal epithelium. In bovine species, attachment is first observed in day 20 trophoblasts that are characterized by the presence of multinucleate epithelial cells by day 24 . Degenerative changes in many uterine epithelial cells are seen at the regions to which the trophectoderm contacts between 22 and 28 days (Wathes \& Wooding 1980). A long preattachment period is characterized, at least in part, by apical expression of mucin 1, cell surface associated (MUC1) with extensive glycosylation, which sterically inhibits cell-cell and cell-extracellular matrix (ECM) interactions (Wesseling et al. 1995, Komatsu et al. 1997). The involvement of ECM proteins, secreted phosphoprotein 1 (SPP1, osteopontin), and MUC1 and transmembrane receptor integrin (ITG) subunits in the trophectoderm adhesion to luminal epithelium has been well characterized in sheep and pigs (Johnson et al. 2001). ITGs are the dominant glycoproteins in adhesion cascades, owing to their ability to bind to ECM ligands to mediate adhesion, cause cytoskeletal reorganization to stabilize adhesion, and transduce cellular signals through numerous signaling intermediates (Yoshinaga 1989, Burghardt et al. 1997, Giancotti \& Ruoslahti 1999). However, gene expression that determines the cell properties of the trophectoderm during this period has not been well characterized.

In humans and mice, trophoblast invasion into the endometrial matrix is subsequent to the blastocyst's adhesion to the uterine wall. To enable invasion competence, it has been postulated that the trophectoderm undergoes a partial epithelial-mesenchymal transition (EMT), which involves downregulation of apicobasal polarity, expression of mesenchymal-type adhesion proteins, reorganization of the cytoskeleton, and expression of matrix metalloproteinases (MMPs; Denker 1993, Thie et al. 1996, Vićovac \& Aplin 1996). In addition, the signaling involved in regulating EMT events aids in allowing adhesion at the apical membrane of the trophectoderm (Hohn \& Denker 2002). Yet, to date, it is unclear exactly how the trophectoderm acquires adhesive and/or invasive competence, and thus how EMT events relate to the noninvasive conceptus implantation still remains speculative.

Rodents have been the primary model for understanding the implantation process (Dey et al. 2004, Lee

et al. 2007). In mice, however, the blastocyst commences the implantation process soon after hatching from the ZP and is implanted in the endometrial stroma following trophoblast penetration through the uterine epithelium. This rapid progress of murine blastocyst implantation makes it difficult to elucidate the mechanisms associated with blastocyst attachment and adhesion to the uterine epithelium. In domestic animals such as porcine, ovine, and bovine species, on the other hand, the trophoblast cells do not penetrate the uterine epithelium but

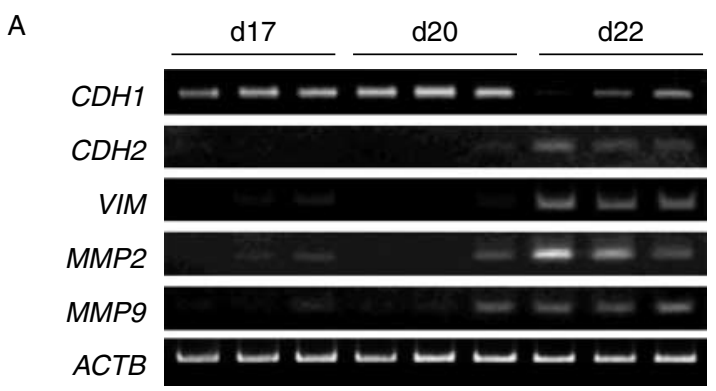

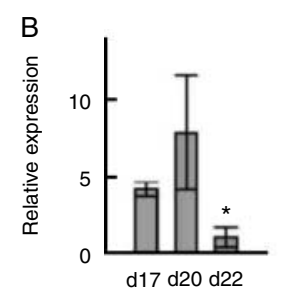

$\mathrm{CDH} 1$
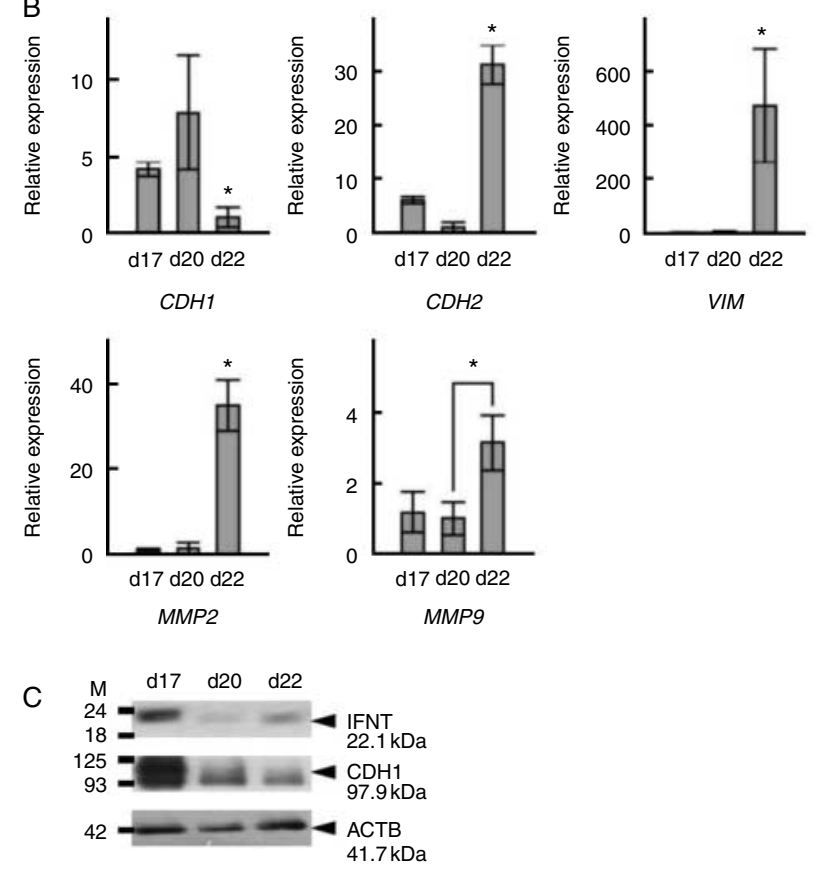

Figure 1 Epithelial and mesenchymal marker mRNAs in bovine conceptuses during the peri-attachment period. (A) Total RNAs extracted from days 17,20 , and 22 conceptuses ( $n=3$ each day) were subjected to RT-PCR analyses for the detection of cadherin 1, type 1, E-cadherin (epithelial) $(C D H 1)$, cadherin 2, type 1, N-cadherin (neuronal) (CDH2), vimentin (VIM), MMP2, and MMP9 transcripts. $A C T B$ mRNA was used as an internal control for RNA integrity. (B) Levels of $C D H 1, C D H 2, V I M, M M P 2$, and MMP9 mRNAs in days 17,20 , and 22 conceptuses ( $n=4$ each day) were examined by quantitative RT-PCR. Reactions were performed in duplicate and the data were analyzed by using the change in cycle threshold value method (Sakurai et al. 2009). ACTB mRNA served as the internal control. ${ }^{*} P<0.05$. (C) Expression of $C D H 1, A C T B$, and IFNT in days 17, 20 , and 22 conceptuses was examined by Western blotting. Three independent experiments were performed for each antibody. 
rather maintain an apical-apical adhesion throughout the implantation process (Chavatte-Palmer \& Guillomot 2007). Understanding the events associated with apicalapical adhesion could provide a new insight into the relationship between trophoblast and uterine cells. Therefore, ruminants could serve as ideal models to study the physiological as well as molecular events through which attachment and adhesion between trophoblast and uterine epithelium proceed.

In the bovine, attachment between trophectodermal epithelium and endometrial epithelium is first seen on day 20 of gestation, and subsequent stable adhesion occurs between days 20 and 22 (Wathes \& Wooding 1980). We hypothesized that molecular events similar to the EMT process would be required to make trophectoderm adhesion to the endometrial epithelium possible. In this paper, we demonstrate that changes in gene expression associated with the EMToccur in the bovine trophectoderm following conceptus attachment to the luminal epithelium.

\section{Results}

\section{Upregulation of EMT markers in day 22 bovine conceptuses}

To evaluate the expression patterns of transcripts typical of the EMT process, cadherin 1, type 1, E-cadherin (epithelial) (CDH1), cadherin 2, type 1, N-cadherin (neuronal) $(\mathrm{CDH} 2)$, and vimentin (VIM) mRNAs in days 17,20 , and 22 conceptuses were evaluated by RT-PCR. High levels of $C D H 2$ and VIM mRNA were found in day 22 conceptuses while the level of $\mathrm{CDH} 1$ decreased (Fig. 1A). Similar changes in these transcripts were also found when RNA extracted from different sets of conceptuses was analyzed by quantitative RT-PCR analysis (Fig. 1B). We also examined MMP2 and MMP9 mRNAs, both of which are implicated in the EMT event during cancer metastasis (Yilmaz \& Christofori 2009). Although bovine implantation is non-invasive, levels of MMP2 and MMP9 transcripts in the bovine conceptus were nevertheless found to be higher on day 22 (Fig. 1B). To support the results obtained from the RT-PCR analysis, Western blot analysis was carried out for $C D H 1$ as well as IFNT, a marker commonly used in this laboratory. $\mathrm{CDH} 1$ protein was low in day 22 conceptuses (Fig. 1C).

\section{Upregulation of EMT regulatory transcription factor mRNAs on day 22 of pregnancy}

Recent studies on cancer metastasis in various cell types have revealed that the process of EMT could be regulated by a number of transcription factors, including SNAI1, SNAI2, ZEB1, ZEB2, KLF8, TCF3, TWIST1, and TWIST2 (Thiery et al. 2009). Hence, we next examined changes in these transcription factor mRNAs in days 17, 20, and 22 conceptuses. RT-PCR analyses found that all of these transcription factor transcripts were present on day 22 (Fig. 2A). On days 17 and 20, SNAI2, ZEB1, ZEB2, TWIST1, TWIST2, and KLF8 mRNAs were low or undetectable, whereas consistent levels of SNAI1 and TCF3 mRNAs were found from days 17 through 22 (Fig. 2A). Upregulation of SNAI2, ZEB1, ZEB2, TWIST1,

A
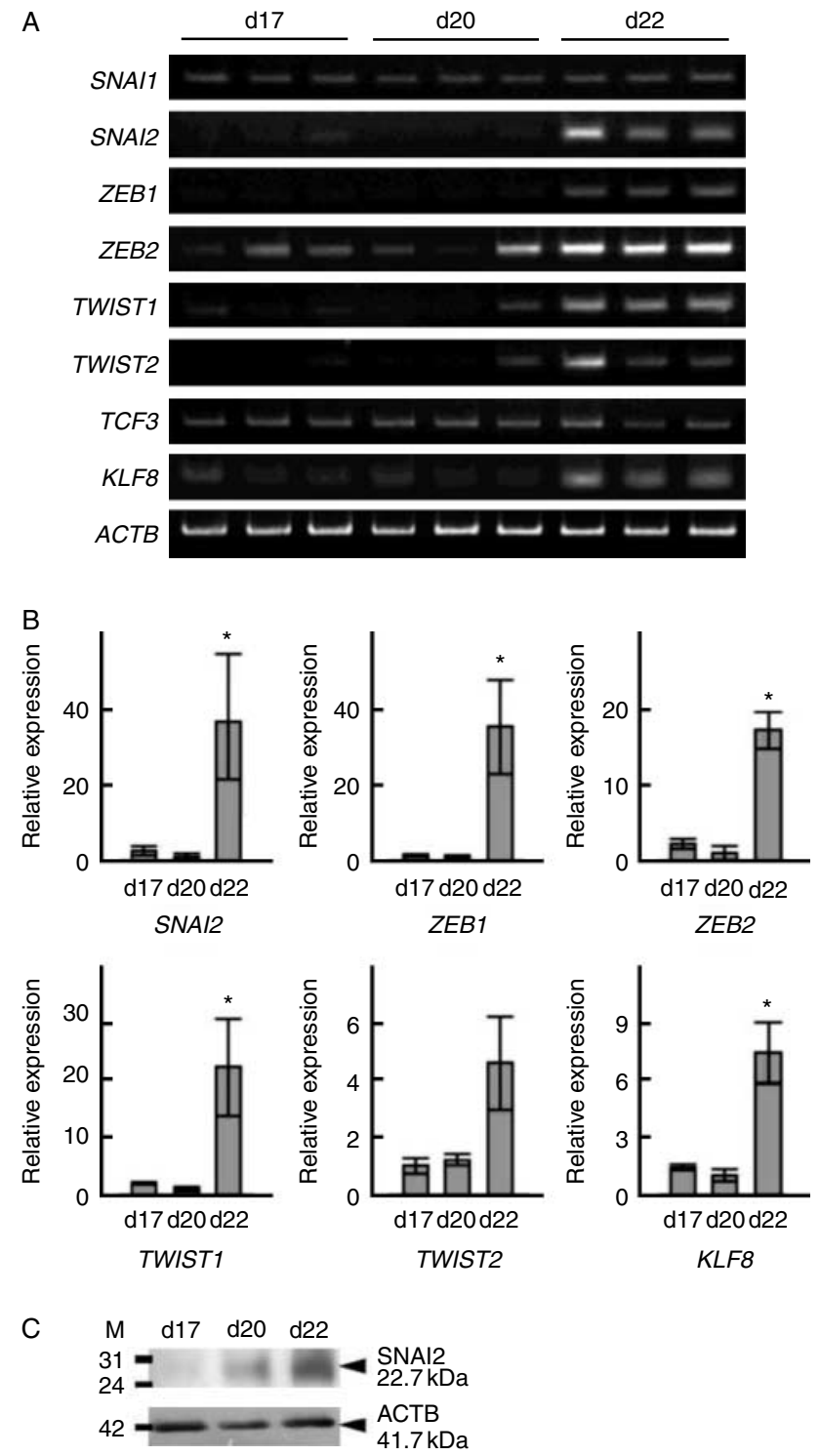

Figure 2 EMT-related transcription factor mRNAs in bovine conceptuses during the peri-attachment period. (A) Total RNAs extracted from days 17,20 , and 22 conceptuses ( $n=3$ each day) were subjected to RT-PCR analyses for the detection of SNAI1, SNAI2, ZEB1, ZEB2, KLF8, TCF3, TWIST1, and TWIST2 transcripts. ACTB mRNA was used as an internal control for RNA integrity. (B) Levels of SNAI2, ZEB1, ZEB2, TWIST1, TWIST2, and KLF8 mRNAs in days 17,20 , and 22 conceptuses $(n=4$ each day) were examined by quantitative RT-PCR. Reactions were performed in duplicate, and the data were analyzed by using the change in cycle threshold value method (Sakurai et al. 2009). ACTB mRNA served as the internal control. ${ }^{*} P<0.05$. (C) Expression of $S N A / 2$ and $A C T B$ in days 17,20 , and 22 conceptuses were examined by western blotting. Three independent experiments were performed for each antibody. 
TWIST2, and KLF8 mRNAs was also confirmed by quantitative RT-PCR (Fig. 2B). Levels of SNAI2 and ZEB1 transcripts on day 22 were $\sim 40$ times greater than those on day 20 (Fig. 2B). In addition, levels of ZEB2 and TWIST1 mRNAs increased $\sim 20$-fold on day 22 compared with those on day 20 (Fig. 2B). Upregulation of these transcription factor mRNAs in day 22 conceptuses was consistent with the occurrence of the EMT event in the trophectoderm of these conceptuses. To support the results from the RT-PCR analysis, Western blotting was carried out to characterize changes in the SNAI2 protein. On day 22, elevated SNAI2 protein levels were consistent with the high levels of SNAI2 mRNA (Fig. 2C).

\section{Expression of EMT marker proteins in day 22 bovine conceptuses}

Upregulation of transcripts associated with the EMT process led us to believe that EMT marker proteins would also be present in day 22 conceptuses. We first performed immunohistochemistry for cytokeratin as an epithelial marker and VIM as a mesenchymal marker on tissue sections from day 22 pregnant uteri. In the uterine endometrium, both luminal and glandular epithelia were positive for cytokeratin and negative for VIM, and the stromal cells were cytokeratin-negative and VIMpositive (Fig. 3). On the other hand, the trophoblast layer of the conceptus was positive for both cytokeratin and VIM (Fig. 3).

The expression of the mesenchymal marker in the trophectoderm led us to evaluate changes in the $\mathrm{CDH} 1$ and/or $\mathrm{CDH} 2$ proteins, which have been identified as key events in the EMT during embryogenesis and carcinogenesis (Thiery 2003, Katoh \& Katoh 2008). Immunolocalization of $\mathrm{CDH} 1$ and $\mathrm{CDH} 2$ revealed that the trophoblast
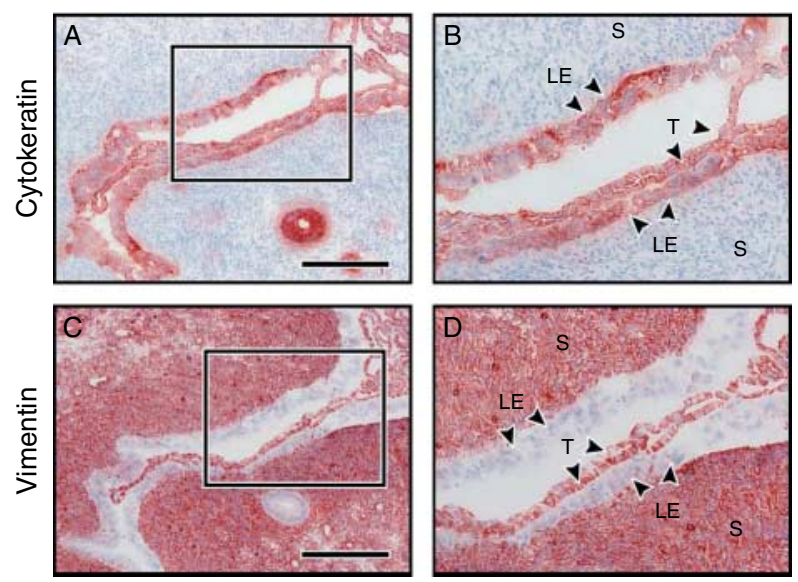

Figure 3 Expression of cytokeratin and vimentin in conceptus and endometrium on day 22. Tissue sections from day 22 uteri $(n=3)$ containing conceptuses were immunostained for (A and B) cytokeratin and $(C$ and $D)$ vimentin. Boxed areas in $A$ and $C$ are presented at a higher magnification in $B$ and $D$ respectively. $T$, trophectoderm; $L E$, (endometrial) luminal epithelium; S, (endometrial) stroma. Scale bar $=200 \mu \mathrm{m}$.
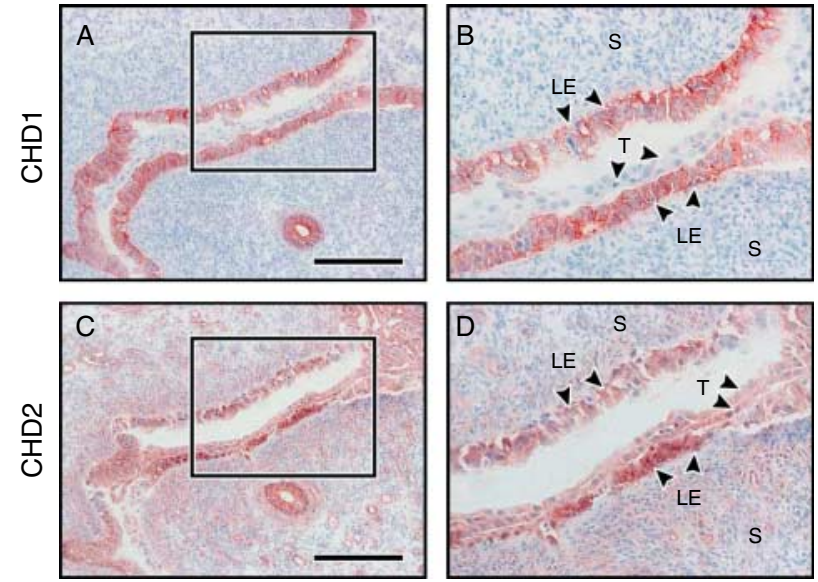

Figure 4 Expression of $\mathrm{CDH} 1$ and $\mathrm{CDH} 2$ in conceptus and endometrium on day 22. Tissue sections from day 22 uteri $(n=3)$ containing conceptuses were immunostained for (A and B) CHD1 and (C and D) $\mathrm{CHD} 2$. Boxed areas in $\mathrm{A}$ and $\mathrm{C}$ are presented at a higher magnification in $B$ and $D$ respectively. $T$, trophectoderm; $L E$, (endometrial) luminal epithelium; S, (endometrial) stroma. Scale bar $=200 \mu \mathrm{m}$.

layer of day 22 conceptus expressed $\mathrm{CDH} 2$, whereas the expression of $\mathrm{CDH} 1$ in the trophectoderm was not detected by immunohistochemistry (Fig. 4). The endometrial stromal cells expressed only $\mathrm{CDH} 2$, whereas both luminal and glandular epithelia of the endometrium expressed both $\mathrm{CDH} 1$ and $\mathrm{CDH} 2$ (Fig. 4). Relatively strong expression of $\mathrm{CDH} 2$ was found on the region of the luminal epithelium where the trophectoderm attached (Fig. 4).

\section{Expression of growth factor receptor mRNAs during the peri-attachment period}

Unique protein expressions found in the trophectoderm layer, including the upregulation of $\mathrm{CDH} 2$ and VIM on day 22, indicated that the epithelial trophectoderm exhibited protein expression commonly associated with the mesenchyme (Figs 3 and 4). However, EMT factor expression was not limited to the portion where the trophoblast layer attached to the luminal epithelium, but was found throughout the conceptus trophectoderm (Figs 3 and 4). To elucidate the molecular mechanisms associated with EMT in non-invasive trophoblasts, several growth factor receptors, through which EMT events are mediated by downstream signaling, were then examined. These included epidermal growth factor receptor (EGFR), fibroblast growth factor receptor 1 (FGFR1), insulin-like growth factor 1 receptor (IGFIR), platelet-derived growth factor receptor, alpha and beta polypeptides (PDGFRA and PDGFRB), and transforming growth factor $\beta$ receptors (TGFBR1 and TGFBR2) (Said \& Williams 2011). The expression of EGFR and TGFBR1 mRNAs was found from days 17 through 22 (Fig. 5A). The expression levels of FGFR1, PDGFRA, PDGFRB, and TGFBR2 mRNAs were low or undetectable on days 17 
A
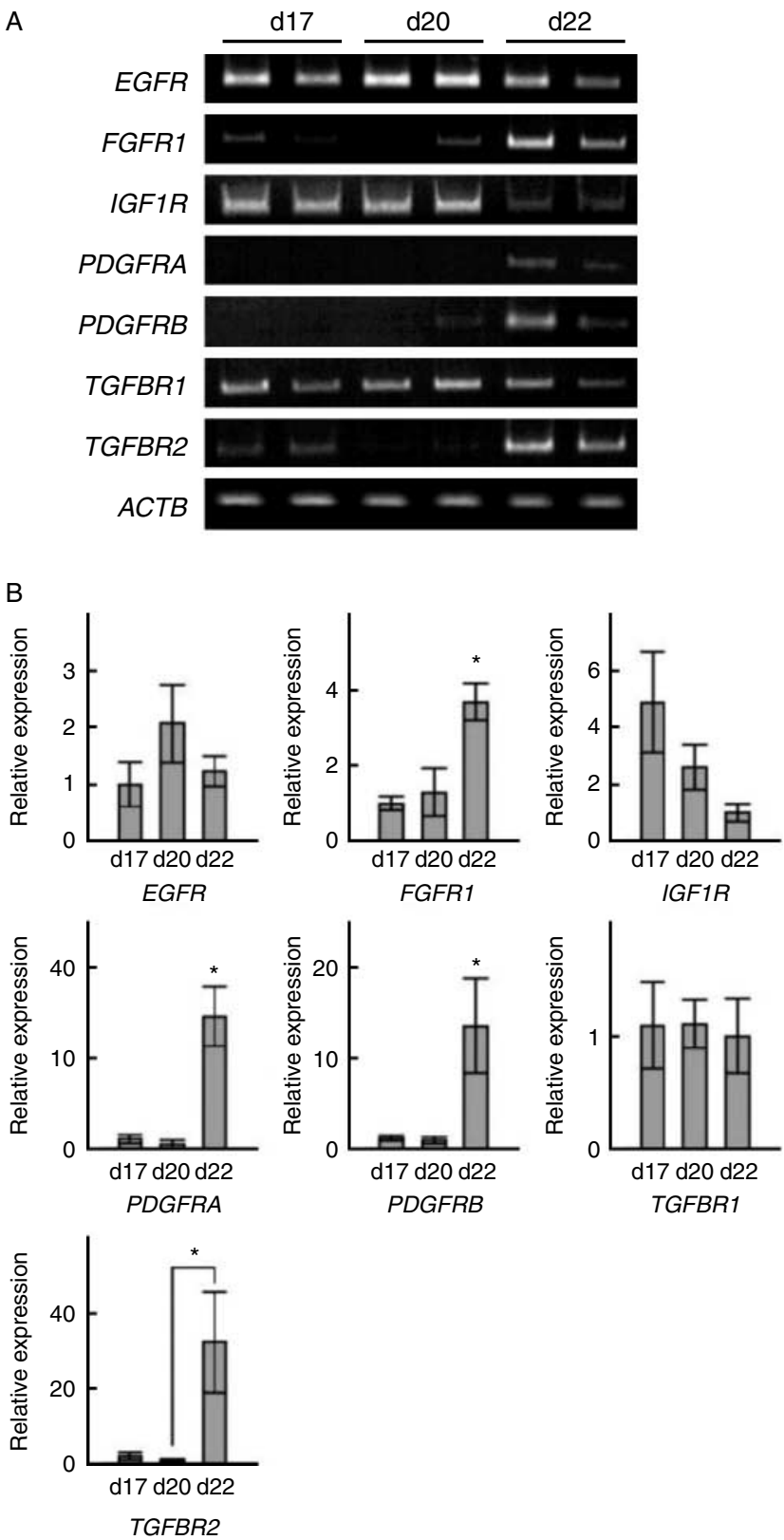

Figure 5 Detection of growth factor receptor mRNAs in bovine conceptuses during the peri-attachment period. (A) Total RNAs extracted from days 17,20 , and 22 conceptuses ( $n=3$ each day) were subjected to RT-PCR analyses for growth factor receptor transcripts. These included epidermal growth factor receptor (EGFR), fibroblast growth factor receptor 1 (FGFR1), insulin-like growth factor-I receptor (IGFIR), platelet-derived growth factor receptors (PDGFRA and PDGFRB), and transforming growth factor $\beta$ receptors (TGFBR1 and TGFBR2). ACTB mRNA was used as an internal control for RNA integrity. (B) Levels of EGFR, FGFR1, IGFIR, PDGFRA, PDGFRB, TGFBR 1, and TGFBR2 mRNAs in days 17, 20, and 22 conceptuses ( $n=4$ each day) were examined by quantitative RT-PCR. Reactions were performed in duplicate and the data were analyzed by using the change in cycle threshold value method (Sakurai et al. 2009). ACTB mRNA served as the internal control. ${ }^{*} P<0.05$. and 20 and became detectable on day 22 (Fig. 5A). Quantitative RT-PCR revealed the upregulation of FGFR1, PDGFRA, PDGFRB, and TGFBR2 mRNAs on day 22 , and the consistent expression of TGFBR $1 \mathrm{mRNA}$ from days 17 through 22 (Fig. 5B).

\section{Expression of $\alpha$ - and $\beta$-subunits of ITG mRNAs in peri-implantation conceptuses}

ITGs are also known to mediate EMT independently or in cooperation with growth factor receptors (Larue \& Bellacosa 2005). We thus examined the levels of $\alpha$ - and $\beta$-subunits of ITG (ITGA4, ITGA5, ITGA8, ITGAV, ITGB1, ITGB3, ITGB5, and ITGB6) mRNAs in the conceptuses. Higher ITGA5, ITGAV, and ITGB1 transcripts were found from days 17 through 22, whereas the expression of ITGB6 mRNA was undetectable (Fig. 6A). Though the expression of ITGA4, ITGA8, ITGB3, and ITGB5 mRNAs was found on day 22, the expression levels on days 17 and 20 were low or undetectable (Fig. 6A). The upregulation of ITGA4 and ITGA 8 transcripts on day 22 and the consistent expression of ITGAV and ITGB1 transcripts were also confirmed by quantitative RT-PCR (Fig. 6B). Using immunohistochemistry, we further examined the expression of ITGA4 on tissue sections from day 22 pregnant uteri and found positive immunostaining on that day (Supplementary Figure 1, see section on supplementary data given at the end of this paper).

\section{Discussion}

The EMT has been recognized to occur as complete EMT or partial EMT, and the latter is characterized by transient loss of epithelial characteristics without full acquisition of mesenchymal characteristics (Leroy \& Mostov 2007). In this study, we demonstrated that after bovine conceptus-endometrium attachment, the trophectoderm expressed VIM while cytokeratin expression was still retained. Since the bovine trophoblast cells from mid-gestational placentomes do not express VIM (Haeger et al. 2010), this coexistence of the epithelial and mesenchymal gene expression in the trophectoderm could be transient and possibly be a prerequisite for the steps from attachment to adhesion. Recently, coexpression of cytokeratin and VIM was also found in the luminal epithelium of long-term progesteronetreated pigs (Bailey et al. 2010). It has been noted that many processes occurring during development and tissue remodeling, as well as in adult organisms, involve a transient loss of epithelial polarity without full acquisition of mesenchymal characteristics. For example, partial EMT has been found in mammary gland development and epithelial wound healing (Leroy \& Mostov 2007). These findings and those in this study are consistent with the notion that there is a spectrum of partial EMT processes in which cells undergo only 
selected EMT steps for a transient period (Grünert et al. 2003, Huber et al. 2005).

Nakano et al. (2005) have reported that $\mathrm{CDH} 1$ expression is distributed within the cytoplasm of trophoblast binucleate cells in the bovine placentome.

A
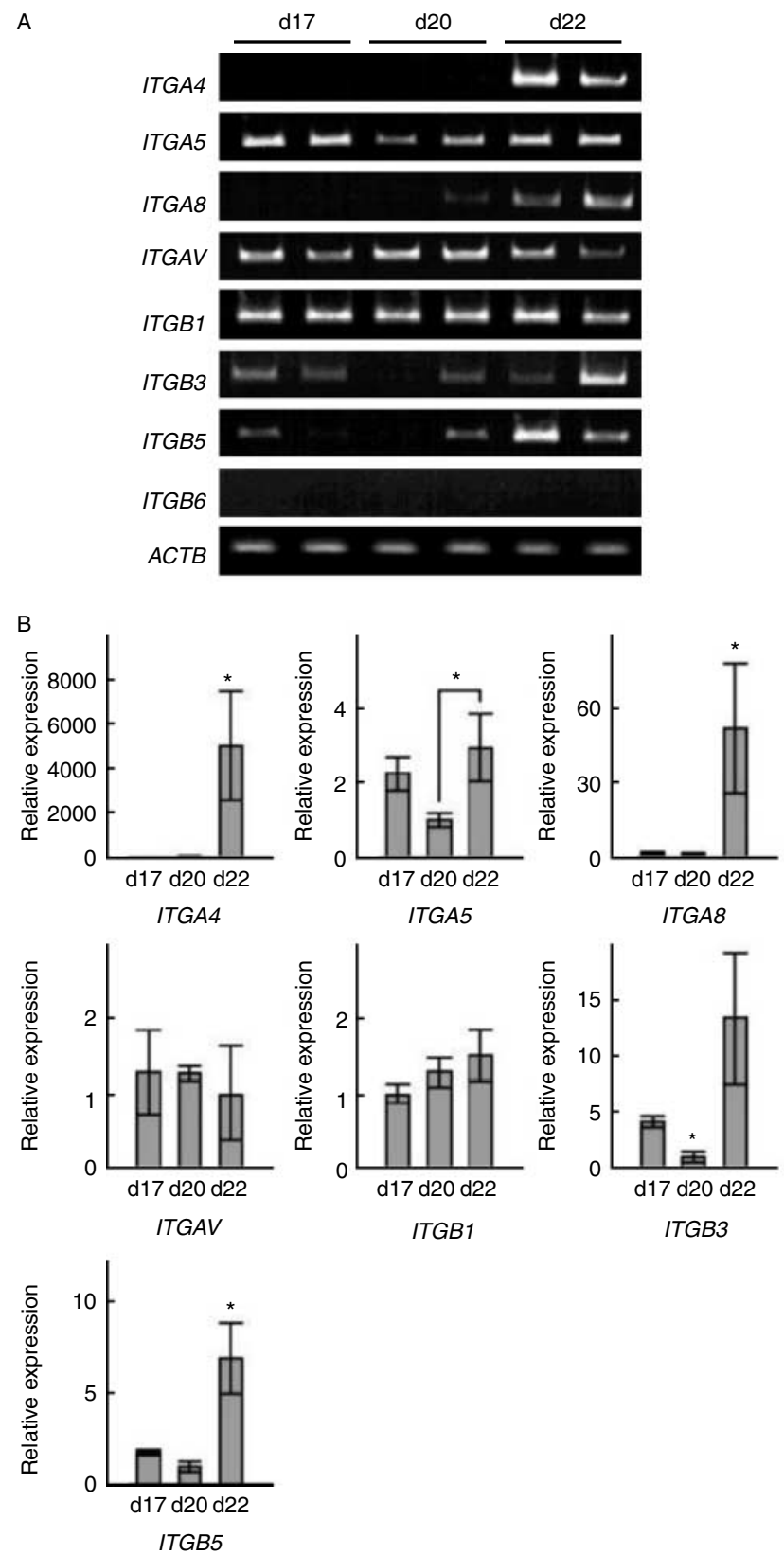

Figure 6 Detection of integrin $\alpha(I T G A)$ and $\beta(I T G B)$ subunit mRNAs in bovine conceptuses during the peri-attachment period. (A) Total RNAs extracted from days 17,20 , and 22 conceptuses ( $n=3$ each day) were subjected to RT-PCR analyses for ITGA4, ITGA5, ITGA8, ITGAV, ITGB1, ITGB3, ITGB5, and ITGB6 transcripts. ACTB mRNA was used as an internal control for RNA integrity. (B) Levels of ITGA4, ITGA5, ITGA8, ITGAV, ITGB1, ITGB3, and ITGB5 mRNAs in days 17, 20, and 22 conceptuses ( $n=4$ each day) were examined by quantitative RT-PCR. Reactions were performed in duplicate and the data were analyzed by using the change in cycle threshold value method (Sakurai et al. 2009). ACTB mRNA served as the internal control. ${ }^{*} P<0.05$.
They have also noted the translocation of $\beta$-catenin into the nuclei of trophoblast binucleate cells, indicating the role of $\mathrm{CDH} 1-\beta$-catenin expression in trophoblast differentiation. It is reported that tyrosine kinases induce the tyrosine phosphorylation and ubiquitination of the $\mathrm{CDH} 1$ complex, which causes endocytosis of $\mathrm{CDH} 1$ (Fujita et al. 2002, Janda et al. 2006). When CDH2 is highly expressed in day 22 trophoblasts, the increase in $\mathrm{CDH} 1$ degradation could also be involved in the further reduction of trophectodermal $\mathrm{CDH} 1$ expression. Hence, the loss of $\mathrm{CDH} 1$ as conceptus attachment to luminal epithelium progresses may play a role in the transition in gene expression required for the successful progression from implantation to placentation.

A number of transcription factors have been reported to regulate the transition in gene expression associated with EMT (Thiery et al. 2009). Among these EMT master regulators, we have identified SNAI2, ZEB1, ZEB2, TWIST1, TWIST2, and KLF8 mRNAs to be upregulated concurrently with cytokeratin expression in the trophectoderm. It has been characterized that SNAI1, ZEB, and KLF8 factors bind to and repress CDH1 promoter activity (Peinado et al. 2007, Wang et al. 2007), whereas TWIST1 and TWIST2 repress $\mathrm{CDH} 1$ transcription indirectly (Yang \& Weinberg 2008). SNAI2, was discovered in the chick as a key regulator of mesoderm formation and neural crest migration, two developmental processes involving EMT (Nieto et al. 1994). In cell cultures, experimental overexpression of SNAI1 or SNAI2 is sufficient to induce epithelial cells to undergo EMT (Savagner et al. 1997, Batlle et al. 2000, Cano et al. 2000, Bolós et al. 2003). However, SNAI1 has been reported to be a more potent inducer of EMT and repressor of $\mathrm{CDH} 1$ than SNAI2 (Batlle et al. 2000). The retention of cytokeratin expression in spite of VIM expression in day 22 trophoblasts could be explained by the increase in SNAI2, not SNAI1, in this study. Moreover, EMT is induced and promoted by extracellular stimuli, including growth factors such as TGF $\beta$ and FGF and ECM protein, and the downstream signaling of their receptors (Said \& Williams 2011). This observation, together with the upregulation of various growth factor receptor TGFBR2, FGFR1, PDGFRA, and $P D G F R B$ transcripts demonstrated in this study, suggests that intrauterine proteins secreted during the process of conceptus-endometrium attachment progression could be responsible for the regulation of EMT in the bovine trophectoderm.

SNAI and ZEB factors are known to induce the expression of MMPs that can degrade the basement membrane, thereby favoring invasion (Thiery et al. 2009). Although bovine trophoblasts do not penetrate into the endometrium, upregulation of MMP2 and MMP9 transcripts suggests that these MMPs play a role in non-invasive trophoblasts. The ligand for FGFR1, FGF1, is known to upregulate MMP13, resulting in EMT induction (Billottet et al. 2008). It is possible that upregulation of MMP2 and MMP9 could be induced 
by various growth factors. In humans and rodents, MMPs play a pivotal role in the process of trophoblast invasion throughout the implantation and placentation periods, which require the degradation and remodeling of ECM at the feto-maternal interface (Cohen et al. 2006). MMPs play a similar role in bovine trophoblasts (Hirata et al.
2003, Kizaki et al. 2008, Dilly et al. 2010). Thus, further investigation on the upstream signaling of the upregulation of MMP2 and MMP9 transcription and their roles during the bovine attachment processes may provide insights into trophoblast behavior in the non-invasive mode of implantation.

Table 1 Primers for RT-PCR and quantitative RT-PCR analyses.

\begin{tabular}{|c|c|c|}
\hline Name (GenBank accession no.) & Sequence & Product length $(b p)$ \\
\hline \multirow[t]{2}{*}{ CDH1 (NM_001002763) } & F: GTGATAGATGTGAATGAAGCCC & 167 \\
\hline & R: AATCCGATACGTGATCTTCTG & \\
\hline \multirow[t]{2}{*}{ CDH2 (NM_001166492) } & F: CCTCTGACAATGGAATCCCT & 137 \\
\hline & R: GAGTTTCACAAATCTCTGCCT & \\
\hline \multirow[t]{2}{*}{ MMP2 (NM_174745) } & F: CTTCAAGGACCGATTCATCTG & 280 \\
\hline & R: CAGTTAAAGGCAGCATCCAC & \\
\hline \multirow[t]{2}{*}{ MMP9 (NM_174744) } & F: TTCCTGGGCAAGGAATACTC & 151 \\
\hline & R: AACAGGCTGTATCCTTGATCC & \\
\hline \multirow[t]{2}{*}{ VIM (NM_173969) } & F: CAAGTCCAAGTTTGCTGACC & 266 \\
\hline & R: TCATGTTCTGAATCTCATCCTG & \\
\hline \multirow[t]{2}{*}{ SNAI1 (NM_001112708) } & F: TTCTCCAGAGCTCACTTTCC & 135 \\
\hline & R: GAGAGTCCCAGATGAGTGTC & \\
\hline \multirow[t]{2}{*}{ SNAI2 (NM_001034538) } & F: CAAGGACACATCAGAACTCAC & 156 \\
\hline & R: CTCTTGCACTGGTATTTCTTGAC & \\
\hline \multirow[t]{2}{*}{ ZEB1 (XM_615192) } & F: ATATTGCTATACCTACCGTCAC & 232 \\
\hline & R: TTGCCTTTCATCCTGATTTCC & \\
\hline \multirow{2}{*}{ ZEB2 (NM_001076192) } & F: AAACTGATGAAGAAGACAAGCC & 299 \\
\hline & R: ACGAGGTAGGACAATTTGAG & \\
\hline \multirow[t]{2}{*}{ KLF8 (XM_603911) } & F: CAAGCATCCGTACTGTTCTG & 284 \\
\hline & R: GGGTTCAACTTTAACTGATCCA & \\
\hline \multirow{2}{*}{ TCF3 (XM_609091) } & F: CCGAAGATGAGAAGAAGGAC & 320 \\
\hline & R: TTAGGGTTCAGGTTACGCTC & \\
\hline \multirow[t]{2}{*}{ TWIST1 (XM_001250357) } & F: GGTACATCGACTTCCTCTACC & 227 \\
\hline & R: GGAAACAATGACATCTAGGTCTC & \\
\hline \multirow[t]{2}{*}{ TWIST2 (NM_001083748) } & F: GCCAGGTACATAGACTTCCTC & 272 \\
\hline & R: GGGTTTCAGAAGTTGCAGAC & \\
\hline \multirow[t]{2}{*}{ ITGA4 (NM_174748.1) } & F: TCTGGCATAGTGAGACTTGAC & 241 \\
\hline & R: GGACTTACAAACCCATGAACTG & \\
\hline \multirow[t]{2}{*}{ ITGA5 (NM_001166500.1) } & F: GTGACGTGGGCCCTGCTGTC & 230 \\
\hline & R: CCGTCTTTGCAGCCGGTGGT & \\
\hline \multirow[t]{2}{*}{ ITGAV (NM_174367.1) } & F: ACTCATTTCCGATCAAGTAGCA & 166 \\
\hline & R: GAAACGAAGTCATCTATGCCA & \\
\hline \multirow{2}{*}{ ITGA8 (XM_002701040) } & F: ATGGACAATGTCACCCGAAT & 172 \\
\hline & R: AATTGCTGTCTGGGTTGTCC & \\
\hline \multirow[t]{2}{*}{ ITGB1 (NM_174368.2) } & F: AAGCCTCTGGGCTTCACTGAGGA & 155 \\
\hline & R: CCGACACGTCCCTCGTTGCA & \\
\hline ITGB3 (XM_616376.3) & F: CGTAAGCTCACCAGTAACCT & 284 \\
\hline & R: GCCAATCTTCTCATCACAGAC & \\
\hline ITGB5 (NM_174679.2) & F: CGGGTCCTTCTGCGAGTGCG & 228 \\
\hline & R: GCСССТGGСТСТGTGСАСТG & \\
\hline ITGB6 (NM_174698) & F: GAACAGCTCCAAGTGCAACA & 194 \\
\hline & R: ACAAGTGGCAGACACACTGC & \\
\hline TGFBR1 (NM_174621) & F: GTTTACCATTGCTTGTTCAGAG & 262 \\
\hline & R: GTGCCATTGTCTTTATTGTCTG & \\
\hline TGFBR2 (NM_001159566) & F: TTCTCCGAAGAGTACACCAG & 291 \\
\hline & R: TGTTGTGGTTGATGTTGTTGG & \\
\hline FGFR1 (NM_001110207) & F: GATGATGACGACGATGACTC & 263 \\
\hline & R: CATAACGGACCTTGTAGCCT & \\
\hline PDGFRA (NM_001192345) & F: GGACAAATGAAAGGCAAAGG & 143 \\
\hline & R: CAGCACATTCGTAATCTCCA & \\
\hline PDGFRB (NM_001075896) & F: CTGTGAAGATGCTGAAATCC & 159 \\
\hline & R: TAGATGGGTCCTCCTTTAGTG & \\
\hline IGF1R (XM_606794) & F: AGAGACATCTATGAGACGGAC & 280 \\
\hline & R: CAGCTCAAACAGCATGTCAG & \\
\hline EGFR (XM_592211) & F: ATGCTCTATGACCCTACCAC & 236 \\
\hline & R: TTCCGTTACAAACTTTGCCA & \\
\hline ACTB (NM_173979.3) & F: TCCCTGGAGAAGAGCTACGA & 255 \\
\hline & R: GGGCAGTGATCTCTTTCTGC & \\
\hline
\end{tabular}

F, forward primer; $R$, reverse primer. 
Our observation showed that the expressions of ITGA4, ITGA8, and ITGB5, which encode the ITG subunits $\alpha 4, \alpha 8$, and $\beta 5$, respectively, were increased in day 22 conceptuses. The $\alpha 4$ and $\alpha 8$ subunits are known to form heterodimers with the $\beta 1$ subunit and interact with osteopontin (SPP1; Schnapp et al. 1995, Bayless et al. 1998), and in combination with the $\alpha \vee$ subunit, the $\beta 5$ subunit is also known to bind to SPP1 (Caltabiano et al. 1999). Among those upregulated ITG subunits, the increase in the expression of ITG $\alpha 4$ was prominent. ITG $\alpha 4 \beta 1$, also known as very late antigen-4 (VLA-4), is normally expressed in leukocytes (Yednock et al. 1992) and is often seen in mesenchymal stem cells (Kumar \& Ponnazhagan 2007). Although the majority of SPP1binding ITGs bind to the RGD (Arg-Gly-Asp) domain of SPP1, $\alpha 4 \beta 1$ ITG interacts with SPP1 through its SVVYGLR (Ser-Val-Val-Tyr-Gly-Leu-Arg) motif (Ito et al. 2009). At the implantation sites in the porcine, the $\alpha \vee \beta 6$ trophectoderm and $\alpha \mathrm{V} \beta 3$ uterine epithelial cell ITGs bind to SPP1 at the apical membranes, and those ITGSPP1 bindings may have a critical role in conceptus implantation to the endometrium (Erikson et al. 2009). Our observation that the particular subunits of SPP1binding ITG are upregulated during the attachment process indicates the possible involvement of SPP1 and its binding partner ITG in the trophoblast adhesion to the endometrial epithelium in the bovine. The prominent expression of ITG $\alpha 4$ may also enable the trophoblast to interact with the SVVYGLR motif of SPP1 even when the RGD domain of SPP1 is occupied by the uterine epithelial cell ITGs. These results suggest that both ECM binding and partial EMT are required for trophoblast adhesion and possibly placental formation in the bovine species.

In conclusion, it has been thought that EMT is the event required for trophoblast migration and invasion to the maternal endometrium in mammals with invasive placentation. Results from this study suggest that, in addition to ECM binding, partial EMT is required for proper adhesion of trophoblasts in non-invasive placentation.

\section{Materials and Methods}

\section{Animals and tissue preparation}

All animal procedures in this study were approved by the Committee for Experimental Animals at Zen-noh Embryo Transfer (ET) Center and the University of Tokyo. Estrous synchronization, superovulation, and ET were performed as described previously (Ideta et al. 2007). Seven-day embryos (day $0=$ day of estrous) were collected from superovulated Japanese black cattle. Thirty embryos derived from the superovulation were transferred non-surgically into the uterine horn of 15 Holstein heifers (two blastocysts/recipient), ipsilateral to the corpus luteum on day 7 of the estrous cycle. For RNA analyses, elongated conceptuses were collected non-surgically by uterine flushing on day 17,20 , or 22 (four animals each) with $500 \mathrm{ml}$ sterile PBS (pH 7.2).
Conceptuses in the uterine flushing media were obtained by centrifugation at $180 \mathrm{~g}$ for $5 \mathrm{~min}$ and snap-frozen in liquid nitrogen. For immunohistochemistry, hysterectomy was performed on day $22(n=3)$, and the uterine tissues containing the conceptus were frozen in dry ice-cooled heptane. Samples were transferred to the Laboratory of Animal Breeding at the University of Tokyo and stored at $-80^{\circ} \mathrm{C}$ until use.

\section{RNA extraction and RT-PCR}

Total RNA was prepared from days 17, 20, and 22 conceptuses with ISOGEN reagent (NIPPON GENE, Tokyo, Japan). cDNAs were each synthesized from total RNA (250 ng) with ReverTra Ace (TOYOBO Co., Ltd, Osaka, Japan) and random primers, diluted ten times with water, and subjected to PCR amplification to estimate mRNA levels. PCR was carried out with 1 or $3 \mu \mathrm{l}$ diluted cDNA reaction mixture, 0.5 units Ex Taq DNA polymerase (Takara Biomedicals, Tokyo, Japan), Ex Taq buffer, $0.2 \mu \mathrm{M}$ oligonucleotide primers described in Table 1, and $0.2 \mathrm{mM}$ deoxyribonucleotide triphosphate (dNTP) in a final volume of $20 \mu \mathrm{l}$. The thermal profile for PCR was at $95{ }^{\circ} \mathrm{C}$ for $2 \mathrm{~min}$, followed by 30 or 35 cycles of $95^{\circ} \mathrm{C}$ for $30 \mathrm{~s}, 57^{\circ} \mathrm{C}$ for $30 \mathrm{~s}$, and $72{ }^{\circ} \mathrm{C}$ for $30 \mathrm{~s}$. The PCR products were separated on a $2.0 \%$ agarose gel containing ethidium bromide and visualized under u.v. light through an image analysis system (ATTO Corporation, Tokyo, Japan).

\section{Quantitative RT-PCR}

Reverse-transcribed cDNA $(3 \mu \mathrm{l})$ was subjected to real-time PCR amplification using 0.1 units Ex Taq HS polymerase (Takara Biomedicals), Ex Taq HS buffer, $0.5 \mu$ M oligonucleotide primers listed in Table 1, $2.5 \mathrm{mM}$ dNTP, SYBR green (SYBR Green I Nucleic Acid Gel Stain, Takara Biomedicals) as fluorescence intercalator, and Rox reference dye (Invitrogen) in a final volume of $20 \mu \mathrm{l}$, and PCR amplification was carried out on an Applied Biosystems 7900HT Real-Time PCR System (Applied Biosystems, Foster City, CA, USA). The thermal profile for real-time PCR was at $95^{\circ} \mathrm{C}$ for $10 \mathrm{~min}$, followed by 40 cycles of $95{ }^{\circ} \mathrm{C}$ for $10 \mathrm{~s}, 60^{\circ} \mathrm{C}$ for $20 \mathrm{~s}$, and $72{ }^{\circ} \mathrm{C}$ for $40 \mathrm{~s}$. Average threshold $\left(C_{\mathrm{t}}\right)$ values for mRNA were calculated and normalized to $C_{\mathrm{t}}$ values for ACTB mRNA (Sakurai et al. 2009). Each run was completed with a melting curve analysis to confirm the specificity of amplification and the absence of primer dimers.

\section{Western blotting}

Western blot analysis was performed using cell lysates from days 17,20 , and 22 conceptuses. Cell lysates $(10 \mu \mathrm{g})$ were loaded into each lane and separated by $10 \%$ SDS-PAGE, transferred onto a polyvinylidene fluoride (PVDF) membrane (Millipore, Bedford, MA, USA), and then treated with rabbit anti-human CDH1 antibody (1:1000; Cell Signaling Technology, Danvers, MA, USA), rabbit polyclonal SNAI2 antibody (1:1000; Abcam, Cambridge, MA, USA), rabbit monoclonal anti-IFNT antibody (1:1000; Operon, Tokyo, Japan) or rabbit polyclonal ACTB antibody (1:1000; Abcam) diluted with Can Get Signal Solution I (TOYOBO Co., Ltd). The proteins were 
detected using the secondary antibody conjugated with HRP (goat antirabbit, 1:10 000; Irritant NA934V) diluted with Can Get Signal Solution II on an ECL Western blotting detection system (Amersham Pharmacia Biotech; Sakurai et al. 2010).

\section{Immunohistochemistry}

Immunohistochemical analyses were performed on $10 \mu \mathrm{m}$ fresh-frozen sections of day 22 uterine tissues. Sections were fixed with 4\% paraformaldehyde/PBS, and endogenous peroxidase was quenched by immersing in $0.3 \%(\mathrm{v} / \mathrm{v})$ hydrogen peroxide/methanol. Streptavidin/biotin blocking kit (VECTOR LABORATORIES, Inc. Burlingame, CA, USA) was used to block endogenous biotin according to the manufacturer's instructions. After 30 min incubation with $10 \%$ normal goat serum, the sections were incubated with rabbit anti-bovine cytokeratin polyclonal antibody (1:100 dilution, catalog no. Z0622; Dako Deutschland $\mathrm{GmbH}$, Hamburg, Germany), mouse anti-human VIM MAB (clone V9, 1:100 dilution, catalog no. M0725; Dako), rabbit antimouse $\mathrm{CDH} 1$ polyclonal antibody (1:100 dilution, catalog no. 3195; Cell Signaling Technology), rabbit anti-human $\mathrm{CDH} 2$ polyclonal antibody (1:100 dilution, catalog no. ab12221; Abcam), or mouse anti-human ITGA4 (ITG alpha 4 chain, VLA-4) antibody (1:100 dilution; AbD Serotec - a division of MorphoSys, Kidlington, UK) overnight at $4{ }^{\circ} \mathrm{C}$. Subsequently, the sections were incubated with either goat antirabbit $\operatorname{lgG}$ biotin conjugate (1:800 dilution, catalog no. B8895; SigmaAldrich) or goat antimouse IgG biotin conjugate (1:1000 dilution, catalog no. B9904; Sigma-Aldrich). The immunoreactivity was visualized by means of avidin-peroxidase (catalog no. E2886; Sigma-Aldrich) and AEC substrate kit (catalog no. 002007; Invitrogen) according to the manufacturer's instructions. The sections were counterstained with hematoxylin and then examined under a light microscope (BX-51; Olympus, Tokyo, Japan).

\section{Statistical analyses}

Statistical analyses were performed using the $\mathrm{R}$ statistical package (www.r-project.org/). All quantitative RT-PCR results were presented as the mean \pm s.E.M. and data were analyzed by ANOVA with general linear model followed by the Tukey contrast tests.

\section{Supplementary data}

This is linked to the online version of the paper at http://dx.doi. org/10.1530/REP-11-0364.

\section{Declaration of interest}

The authors declare that there is no conflict of interest that could be perceived as prejudicing the impartiality of the research reported.

\section{Funding}

This work was supported by a Grant-in-Aid for Scientific Research (18108004) to K Imakawa from the Japan
Society for the Promotion of Science and by the Program for Promotion of Basic Research Activities for Innovative Bioscience (BRAIN).

\section{Acknowledgements}

The authors would like to thank Mr Robert Moriarty for his critical reading of the manuscript. They also thank Dr Kazuyuki Uchida (Graduate School of Agricultural and Life Sciences, The University of Tokyo) for his assistance in the histological assay.

\section{References}

Amoroso EC 1968 The evolution of viviparity. Journal of the Royal Society of Medicine 61 1188-1200.

Bailey DW, Dunlap KA, Frank JW, Erikson DW, White BG, Bazer FW, Burghardt RC \& Johnson GA 2010 Effects of long-term progesterone on developmental and functional aspects of porcine uterine epithelia and vasculature: progesterone alone does not support development of uterine glands comparable to that of pregnancy. Reproduction 140 583-594. (doi:10.1530/REP-10-0170)

Batlle E, Sancho E, Francí C, Domínguez D, Monfar M, Baulida J \& García De Herreros A 2000 The transcription factor snail is a repressor of $\mathrm{CDH} 1$ gene expression in epithelial tumour cells. Nature Cell Biology 2 84-89. (doi:10.1038/35000034)

Bayless KJ, Meininger GA, Scholtz JM \& Davis GE 1998 Osteopontin is a ligand for the alpha4beta1 integrin. Journal of Cell Science $\mathbf{1 1 1}$ $1165-1174$

Bazer FW, Spencer TE, Johnson GA, Burghardt RC \& Wu G 2009 Comparative aspects of implantation. Reproduction 138 195-209. (doi:10.1530/REP-09-0158)

Biggers JD, Bell JE \& Benos DJ 1988 Mammalian blastocyst: transport functions in a developing epithelium. American Journal of Physiology 255 C419-C432.

Billottet C, Tuefferd M, Gentien D, Rapinat A, Thiery JP, Broët P \& Jouanneau J 2008 Modulation of several waves of gene expression during FGF-1 induced epithelial-mesenchymal transition of carcinoma cells. Journal of Cellular Biochemistry 104 826-839. (doi:10.1002/jcb. 21667)

Bolós V, Peinado H, Pérez-Moreno MA, Fraga MF, Esteller M \& Cano A 2003 The transcription factor Slug represses $\mathrm{CDH} 1$ expression and induces epithelial to mesenchymal transitions: a comparison with Snail and E47 repressors. Journal of Cell Science 116 499-511. (doi:10.1242/ jcs.00224)

Bowen JA \& Burghardt RC 2000 Cellular mechanisms of implantation in domestic farm animals. Seminars in Cell \& Developmental Biology 11 93-104. (doi:10.1006/scdb.2000.0155)

Burghardt RC, Bowen JA, Newton GR \& Bazer FW 1997 Extracellular matrix and the implantation cascade in pigs. Journal of Reproduction and Fertility Supplement 52 151-164.

Caltabiano S, Hum WT, Attwell GJ, Gralnick DN, Budman LJ, Cannistraci AM \& Bex FJ 1999 The integrin specificity of human recombinant osteopontin. Biochemical Pharmacology 58 1567-1578. (doi:10.1016/S0006-2952(99)00251-8)

Cano A, Pérez-Moreno MA, Rodrigo I, Locascio A, Blanco MJ, del Barrio MG, Portillo F \& Nieto MA 2000 The transcription factor snail controls epithelial-mesenchymal transitions by repressing $\mathrm{CDH} 1$ expression. Nature Cell Biology 2 76-83. (doi:10.1038/35000025)

Chavatte-Palmer P \& Guillomot M 2007 Comparative implantation and placentation. Gynecologic and Obstetric Investigation 64 166-174. (doi:10.1159/000101742)

Cohen M, Meisser A \& Bischof P 2006 Metalloproteinases and human placental invasiveness. Placenta 27 783-793. (doi:10.1016/j.placenta. 2005.08.006)

Denker HW 1993 Implantation: a cell biological paradox. Journal of Experimental Zoology 266 541-558. (doi:10.1002/jez.1402660606) 
Dey SK, Lim H, Das SK, Reese J, Paria BC, Daikoku T \& Wang H 2004 Molecular cues to implantation. Endocrine Reviews 25 341-373. (doi:10.1210/er.2003-0020)

Dilly M, Hambruch N, Haeger JD \& Pfarrer C 2010 Epidermal growth factor (EGF) induces motility and upregulates MMP-9 and TIMP-1 in bovine trophoblast cells. Molecular Reproduction and Development 77 622-629. (doi:10.1002/mrd.21197)

Erikson DW, Burghardt RC, Bayless KJ \& Johnson GA 2009 Secreted phosphoprotein 1 (SPP1, osteopontin) binds to integrin alpha v beta 6 on porcine trophectoderm cells and integrin alpha $\vee$ beta 3 on uterine luminal epithelial cells, and promotes trophectoderm cell adhesion and migration. Biology of Reproduction 81 814-825. (doi:10.1095/biolreprod.109.078600)

Fleming TP, Sheth B \& Fesenko I 2001 Cell adhesion in the preimplantation mammalian embryo and its role in trophectoderm differentiation and blastocyst morphogenesis. Frontiers in Bioscience 6 1000-1007. (doi:10. 2741/Fleming)

Fujita Y, Krause G, Scheffner M, Zechner D, Leddy HEM, Behrens J, Sommer T \& Birchmeier W 2002 Hakai, a c-Cbl-like protein, ubiquitinates and induces endocytosis of the $\mathrm{CDH} 1$ complex. Nature Cell Biology 4 222-231. (doi:10.1038/ncb758)

Giancotti FG \& Ruoslahti E 1999 Integrin signaling. Science 285 1028-1032. (doi:10.1126/science.285.5430.1028)

Grünert S, Jechlinger M \& Beug H 2003 Diverse cellular and molecular mechanisms contribute to epithelial plasticity and metastasis. Nature Reviews. Molecular Cell Biology 4 657-665. (doi:10.1038/nrm1175)

Haeger JD, Hambruch N, Dilly M, Froehlich R \& Pfarrer C 2010 Formation of bovine placental trophoblast spheroids. Cells, Tissues, Organs 193 274-284. (doi:10.1159/000320544)

Hirata M, Sato T, Tsumagari M, Shimada A, Nakano H, Hashizume K \& Ito A 2003 Differential regulation of the expression of matrix metalloproteinases and tissue inhibitors of metalloproteinases by cytokines and growth factors in bovine endometrial stromal cells and trophoblast cell line BT-1 in vitro. Biology of Reproduction 68 1276-1281. (doi:10.1095/biolreprod.102.006452)

Hohn HP \& Denker HW 2002 Experimental modulation of cell-cell adhesion, invasiveness and differentiation in trophoblast cells. Cells, Tissues, Organs 172 218-236. (doi:10.1159/000066965)

Huber MA, Kraut N \& Beug H 2005 Molecular requirements for epithelialmesenchymal transition during tumor progression. Current Opinion in Cell Biology 17 548-558. (doi:10.1016/j.ceb.2005.08.001)

Ideta A, Urakawa M, Aoyagi Y \& Saeki K 2007 Early development in utero of bovine nuclear transfer embryos using early G1 and G0 phase cells. Cloning Stem Cells 9 571-580. (doi:10.1089/clo.2007.0017)

Ito K, Kon S, Nakayama Y, Kurotaki D, Saito Y, Kanayama M, Kimura C, Diao H, Morimoto J, Matsui Y et al. 2009 The differential amino acid requirement within osteopontin in alpha4 and alpha9 integrin-mediated cell binding and migration. Matrix Biology 28 11-19. (doi:10.1016/j. matbio.2008.10.002)

Janda E, Nevolo M, Lehmann K, Downward J, Beug H \& Grieco M 2006 Raf plus TGFbeta-dependent EMT is initiated by endocytosis and lysosomal degradation of CDH1. Oncogene 25 7117-7130. (doi:10.1038/sj.onc. 1209701)

Johnson GA, Bazer FW, Jaeger LA, Ka H, Garlow JE, Pfarrer C, Spencer TE \& Burghardt RC 2001 Muc-1, integrin, and osteopontin expression during the implantation cascade in sheep. Biology of Reproduction 65 820-828. (doi:10.1095/biolreprod65.3.820)

Kang HM, Kim K, Kwon HB \& Cho WK 1990 Regulation of laminin gene expression in the expansion of mouse blastocysts. Molecular Reproduction and Development 27 191-199. (doi:10.1002/mrd. 1080270303)

Katoh Y \& Katoh M 2008 Hedgehog signaling, epithelial-to-mesenchymal transition and miRNA. International Journal of Molecular Medicine 22 $271-275$.

Kizaki K, Ushizawa K, Takahashi T, Yamada O, Todoroki J, Sato T, Ito A \& Hashizume K 2008 Gelatinase (MMP-2 and -9) expression profiles during gestation in the bovine endometrium. Reproductive Biology and Endocrinology 6 66. (doi:10.1186/1477-7827-6-66)

Komatsu M, Carraway CA, Fregien NL \& Carraway KL 1997 Reversible disruption of cell-matrix and cell-cell interactions by overexpression of sialomucin complex. Journal of Biological Chemistry 272 33245-33254. (doi:10.1074/jbc.272.52.33245)
Kumar S \& Ponnazhagan S 2007 Bone homing of mesenchymal stem cells by ectopic alpha 4 integrin expression. FASEB Journal 21 3917-3927. (doi:10.1096/fj.07-8275com)

Larue L \& Bellacosa A 2005 Epithelial-mesenchymal transition in development and cancer: role of phosphatidylinositol $3^{\prime}$ kinase/ AKT pathways. Oncogene 24 7443-7454. (doi:10.1038/sj.onc.1209091)

Lee KY, Jeong JW, Tsai SY, Lydon JP \& DeMayo FJ 2007 Mouse models of implantation. Trends in Endocrinology and Metabolism 18 234-239. (doi:10.1016/j.tem.2007.06.002)

Leroy P \& Mostov KE 2007 Slug is required for cell survival during partial epithelial-mesenchymal transition of HGF-induced tubulogenesis. Molecular Biology of the Cell 18 1943-1952. (doi:10.1091/mbc.E06-090823)

Nakano H, Shimada A, Imai K, Takahashi T \& Hashizume K 2005 The cytoplasmic expression of $\mathrm{CDH} 1$ and beta-catenin in bovine trophoblasts during binucleate cell differentiation. Placenta $\mathbf{2 6}$ 393-401. (doi:10.1016/j.placenta.2004.08.002)

Nieto MA, Sargent MG, Wilkinson DG \& Cooke J 1994 Control of cell behavior during vertebrate development by Slug, a zinc finger gene. Science 264 835-839. (doi:10.1126/science.7513443)

Nishioka N, Inoue K, Adachi K, Kiyonari H, Ota M, Ralston A, Yabuta N, Hirahara S, Stephenson RO, Ogonuki N et al. 2009 The Hippo signaling pathway components Lats and Yap pattern Tead4 activity to distinguish mouse trophectoderm from inner cell mass. Developmental Cell $\mathbf{1 6}$ 398-410. (doi:10.1016/j.devcel.2009.02.003)

Peinado H, Olmeda D \& Cano A 2007 Snail, Zeb and bHLH factors in tumour progression: an alliance against the epithelial phenotype. Nature Reviews. Cancer 7 415-428. (doi:10.1038/nrc2131)

Said NABM \& Williams ED 2011 Growth factors in induction of epithelialmesenchymal transition and metastasis. Cells, Tissues, Organs 193 85-97. (doi:10.1159/000320360)

Sakurai T, Sakamoto A, Muroi Y, Bai H, Nagaoka K, Tamura K, Takahashi T, Hashizume K, Sakatani M, Takahashi M et al. 2009 Induction of endogenous interferon tau gene transcription by CDX2 and high acetylation in bovine nontrophoblast cells. Biology of Reproduction 80 1223-1231. (doi:10.1095/biolreprod.108.073916)

Sakurai T, Bai H, Konno T, Ideta A, Aoyagi Y, Godkin JD \& Imakawa K 2010 Function of a transcription factor CDX2 beyond its trophectoderm lineage specification. Endocrinology 151 5873-5881. (doi:10.1210/en. 2010-0458)

Savagner P, Yamada KM \& Thiery JP 1997 The zinc-finger protein slug causes desmosome dissociation, an initial and necessary step for growth factor-induced epithelial-mesenchymal transition. Journal of Cell Biology 137 1403-1419. (doi:10.1083/jcb.137.6.1403)

Schnapp LM, Hatch N, Ramos DM, Klimanskaya IV, Sheppard D \& Pytela R 1995 The human integrin alpha 8 beta 1 functions as a receptor for tenascin, fibronectin, and vitronectin. Journal of Biological Chemistry 270 23196-23202. (doi:10.1074/jbc.270.39.23196)

Thie M, Fuchs P \& Denker HW 1996 Epithelial cell polarity and embryo implantation in mammals. International Journal of Developmental Biology 40 389-393.

Thiery JP 2003 Cell adhesion in development: a complex signaling network. Current Opinion in Genetics \& Development 13 365-371. (doi:10.1016/ S0959-437X(03)00088-1)

Thiery JP, Acloque H, Huang RY \& Nieto MA 2009 Epithelial-mesenchymal transitions in development and disease. Cell 139 871-890. (doi:10.1016/ j.cell.2009.11.007)

Thorsteinsdóttir S 1992 Basement membrane and fibronectin matrix are distinct entities in the developing mouse blastocyst. Anatomical Record 232 141-149. (doi:10.1002/ar.1092320116)

Vićovac L \& Aplin JD 1996 Epithelial-mesenchymal transition during trophoblast differentiation. Acta Anatomica 156 202-216. (doi:10.1159/ 000147847)

Wang X, Zheng M, Liu G, Xia W, McKeown-Longo PJ, Hung MC \& Zhao J 2007 Krüppel-like factor 8 induces epithelial to mesenchymal transition and epithelial cell invasion. Cancer Research 67 7184-7193. (doi:10. 1158/0008-5472.CAN-06-4729)

Wathes DC \& Wooding FB 1980 An electron microscopic study of implantation in the cow. American Journal of Anatomy 159 285-306. (doi:10.1002/aja.1001590305) 
Wesseling J, van der Valk SW, Vos HL, Sonnenberg A \& Hilkens J 1995 Episialin (MUC1) overexpression inhibits integrin-mediated cell adhesion to extracellular matrix components. Journal of Cell Biology 129 255-265. (doi:10.1083/jcb.129.1.255)

Yang J \& Weinberg RA 2008 Epithelial-mesenchymal transition: at the crossroads of development and tumor metastasis. Developmental Cell 14 818-829. (doi:10.1016/j.devcel.2008.05.009)

Yednock TA, Cannon C, Fritz LC, Sanchez-Madrid F, Steinman L \& Karin N 1992 Prevention of experimental autoimmune encephalomyelitis by antibodies against alpha 4 beta 1 integrin. Nature 356 63-66. (doi:10. 1038/356063a0)
Yilmaz M \& Christofori G 2009 EMT, the cytoskeleton, and cancer cell invasion. Cancer Metastasis Reviews 28 15-33. (doi:10.1007/s10555008-9169-0)

Yoshinaga K 1989 Receptor concept in implantation research. Progress in Clinical and Biological Research 294 379-387.

Received 28 September 2011

First decision 18 October 2011

Revised manuscript received 2 December 2011

Accepted 7 December 2011 